\title{
ANÁLISE DOS SONHOS E SENTIMENTOS: ESTUDO DE CASO EM UMA ESCOLA MUNICIPAL DE IMPERATRIZ - MA
}

\section{ARTIGO ORIGINAL}

ARAUJO, Marli Da Silva ${ }^{1}$

SANTOS, Nícia De Oliveira ${ }^{2}$

ARAUJO, Marli Da Silva. SANTOS, Nícia De Oliveira. Análise dos sonhos e sentimentos: Estudo de caso em uma Escola Municipal de Imperatriz - MA. Revista Científica Multidisciplinar Núcleo do Conhecimento. Ano 05, Ed. 10, Vol. 20, pp. 59-75. Outubro de 2020. ISSN: 2448-0959, Link de acesso: https://www.nucleodoconhecimento.com.br/educacao/analise-dos-sonhos

\section{RESUMO}

Este artigo teve como objetivo uma maior compreensão sobre as formas de pensar sentir e de sonhar dos alunos do $4^{\circ}$ e $5^{\circ}$ ano, de uma Escola Municipal situada na zona rural de Imperatriz - MA, que vivem sob a condicionalidade da pobreza. Foi feito uma breve análise da pobreza no Brasil e no Maranhão, percebemos que muitas mudanças vêm ocorrendo na política pública brasileira, no sentido de mudar a realidade de muitas crianças e jovens em situação de pobreza ou extrema pobreza. Citamos a educação brasileira como um importante marco histórico. Destacamos a pobreza nas escolas públicas e a possibilidade desses educandos de aprenderem e criar conhecimentos importantes para a vida futura. A educação e garantias da cidadania de crianças e adolescentes, é vista como forma de construção coletiva. A pesquisa foi desenvolvida em uma abordagem qualitativa, com enfoque fenomenológico, e na coleta de dados foram utilizadas entrevistas semiestruturadas.

\footnotetext{
${ }_{1}^{1}$ Pedagoga e especialista em Educação, Pobreza e Desigualdade Social.

2 Orientadora. Mestre em Comunicação, Cultura e Cidadania pela Universidade Federal de Goiás.
} 
Pois se fez necessário, dar oportunidade aos educandos de se expressarem livremente sobre seus sonhos e desejos de um futuro sem pobreza. Teve-se o contato com a realidade dos alunos e de suas famílias, conhecemos a escola onde os educandos estudam e um pouco sobre seus sonhos, desejos e visão de um futuro sem pobreza. Dada à relevância do referencial teórico foi feita análise de documentos e autores que tratam do assunto, como: Arroyo (2015), Freire (2005), Leite (2017), Pinzani e Leão Rego (2015), Reis (2011), dentre e outros.

Palavras-chave: Sonhos, sentimentos, pobreza, educação, cidadania.

\section{INTRODUÇÃO}

Podemos dizer que crianças e jovens em situação de pobreza, passam por momentos como infância, juventude e forma um grupo social diverso, vive e convive com diferentes grupos sociais com desejos e comportamentos diversificados. Ao passo que as crianças em situação de vulnerabilidade social veem na educação, a possibilidade de saírem do ciclo de pobreza em que vivem. A educação como caminho de mudanças e a escola como instituição social, propõe aos os educandos o exercício da cidadania, através das vivencias sociais do cotidiano, a fim de adotar atitudes e comportamentos que possibilitem melhorar as condições de vida de milhares de empobrecidos.

A escola garante o direito de crianças e jovens de conhecerem suas próprias histórias, de se sentirem orgulhosos (as) por fazerem parte de um coletivo, que mesmo sendo explorados e oprimidos nunca deixam de lutar por seus sonhos, na conquista de um futuro pessoal e profissional, direito básico de todo ser humano. A experiência vivenciada no ambiente escolar é fundamental para a construção de conhecimentos e para uma vida melhor, pois aprendizagem sistematizada é um caminho sobre o qual todo ser humano necessita passar, para sentir-se apto a desenvolver todo e qualquer papel perante a sociedade.

Frente à pobreza e desigualdade social que vivenciam muitas pessoas, a importância da educação como processo social, consiste numa atividade global com todos os 
indivíduos na sociedade. De forma que a educação dos menos favorecidos foi essencialmente contemplada pelos autores Paulo Freire, Miguel G. Arroyo, Walquíria Leão Rego, Alessandro Pinzani e outros autores que tratam a respeito deste assunto. $\mathrm{O}$ destaque recebido reafirma o direito à educação pública de qualidade e gratuita a todas as pessoas, na tentativa de corrigir as desigualdades sociais.

Este trabalho teve como objetivo, compreender a realidade referente aos aspectos da pobreza e desigualdade social, que vivenciam crianças, adolescentes e jovens de muitas escolas públicas municipais no Maranhão. Foi dando ênfase a Escola Municipal da Amizade situada na zona rural de Imperatriz - MA. Através dos autores estudados, pudemos compreender melhor as questões que envolvem a pobreza de muitas famílias, brasileiras principalmente na região Nordeste, com ênfase para o Estado do Maranhão, onde os casos de pobreza são mais evidentes.

O referente estudo é organizado em tópicos como: introdução; breve análise da educação no Brasil, e a garantia de cidadania de crianças, adolescentes e jovens; análise da pobreza no Brasil, no Maranhão e a pobreza nas escolas públicas; o percurso metodológico e a análise dos dados coletados. Diante da relevância dos assuntos estudados no decorrer dos módulos da Especialização em Educação, Pobreza e Desigualdade Social, fez-se necessário uma investigação mais cuidadosa sobre os sonhos e sentimentos de crianças e adolescentes que vivenciam situações de pobreza na escola onde esses alunos estudam.

\section{BREVE HISTORIO DA EDUCAÇÃO NO BRASIL}

A educação brasileira se iniciou com a chegada dos Portugueses e da família real ao Brasil no período colonial, por meios dos jesuítas em 1549. As primeiras ações dos jesuítas foram criar as escolas de primeiras letras, com a intenção de catequizar os índios, o método pedagógico que eles aplicaram foi à escolástica e o humanismo, como valores educacionais. Ao passo que os jesuítas, foram responsáveis pela educação no Brasil durante muitos anos. Nesse sentido, Ghiraldelli Jr. (2001) cita que: 
Já em meados dos anos vinte, os intelectuais brasileiros interessados em educação puderam ler, entre outros autores, como o filósofo norteamericano John Dewey que, em 1896, nos Estados Unidos, criou a University Elementary School, acoplada à Universidade de Chicago. De forma que, John Dewey foi educador, reformista social e filósofo do pragmatismo americano. Como um campo experimental da educação nova ou pedagogia nova ou, ainda, a pedagogia da escola nova (GHIRALDELLI JR, 2001, p. 22).

Nessa perspectiva a educação brasileira passou pelos processos de institucionalização do ensino, pelo regime militar, até a transição democrática. Ou seja, foram vários os caminhos até chegar ao século vinte, que depois de um longo período de conturbação na política brasileira, teve várias reformas educacionais. Ghiraldelli Jr. (2001) comenta ainda que, "“...] a primeira república que durou quarenta anos (1889-1930), não veio por meio de um grande movimento popular, assim como a segunda república (1930-1937)". Nesse sentido, podemos citar como exemplo o Manifesto dos Pioneiros da Educação Nova, que potencializou a notoriedade de alguns intelectuais já conhecidos e registrou no campo do prestígio social, as propostas Pedagógicas dos anos trinta.

A partir das reformas educacionais e do processo de modernização e redemocratização da educação, e outras constituições brasileiras como a de 1934 e a de 1946 por exemplo, foi criada e aprovada a Constituição Brasileira de 1988, que significou a garantia de vários direitos sociais a todas as pessoas. Dentre esses direitos estão à gratuidade do ensino público em estabelecimentos oficiais de ensino, o ensino fundamental obrigatório e gratuito para crianças a partir dos quatro anos de idade, autonomia universitária, dentre outros como especifica o Art. 205 da Constituição Federal (1988):

Educação, direito de todos e dever do Estado e da família, será promovida e incentivada com a colaboração da sociedade, visando ao pleno desenvolvimento da pessoa, seu preparo para o exercício da cidadania e sua qualificação para o trabalho. (BRASIL, 1988, p. 121).

Logo, esses direitos são reafirmados na Lei de Diretrizes e Bases da Educação Nacional - LDB, Lei o 9.394 de 20 de dezembro de 1996, na qual foi reservado um capítulo exclusivo para tratar a respeito da educação, como sendo direito de todos os 
cidadãos e dever do Estado para o pleno desenvolvimento da pessoa. De forma que a educação em si já é condição necessária ao exercício da cidadania, e todas as pessoas independentemente de suas especificidades tem seus direitos garantidos. $O$ Art. $2^{\circ}$ da LDB afirma:

A educação é dever da família e do Estado, inspirada nos princípios de liberdade e nos ideais de solidariedade humana, tem por finalidade o pleno desenvolvimento do educando, seu preparo para o exercício da cidadania e sua qualificação para o trabalho. (BRASIL, 1996, p. 53).

Segundo Freire (2005), na sociedade de classe há uma opressão entre opressor e oprimido, onde o opressor (sistema social de classe) que desumanizado impõe-se como ser mais, na busca pela manutenção de seu interesse e de poder sobre o oprimido. Já o oprimido (classe dos menos favorecidos) como ser menos, busca a mudança, a transformação social humanizada. Isto é, procura romper com os processos alienantes diante do opressor. "Os homens humanizam-se trabalhando para fazer o mundo, sempre mais, a mediação de consciência que se coexistênciam em liberdade [...]" (FREIRE, 2005, p. 11). De modo que os homens se libertam em comunhão, pois o processo de libertação não se trata apenas de ativismo, é necessário reflexão para que a transformação de fato aconteça. Além disso, a educação é transformação de uma vida sem perspectivas, é se libertar das imposições sociais que a sociedade impõe aos menos favorecidos.

Nesse mesmo sentido Arroyo (2010) nos fala dos diversos desiguais, as pessoas pobres que vivem nas ruas, a empregada doméstica e outras pessoas vítimas das desigualdades sociais. De modo que pode ser incorporada à escola plural, pois o objetivo é fazer com que esses alunos sintam que a escola é seu lugar. A escola é o lugar onde todos os alunos devem sentir-se acolhidos, um lugar humano. "A sociedade cobra das escolas e seus(suas) mestres(as) a solução de um problema produzido nesses contextos sociais, políticos e econômicos [...]" (ARROYO, 2015, p. 10). Isto é, os professores teriam que ir muito além dos muros escola, e não serem apontados como se fossem os únicos responsáveis pela moralização do educando. 


\subsection{EDUCAÇÃO E CIDADANIA}

É consenso que a educação e cidadania andam juntas, é uma construção coletiva e constante que requer uma verdadeira participação da sociedade, é à acolhida de todos sem especificidades, é a preocupação com a saúde, educação, meio ambiente, saneamento básico, com a melhoria de vida das pessoas, carentes, inclusão social, dentre outros. Os cidadãos não devem se acomodar e esperar que os governos ajam sozinhos sobre os interesses de toda uma nação, ou apenas falar dos problemas políticos do país sem agir. Conforme menciona Tonet (2005), é a convicção de articular a educação com o processo de construção da cidadania, pois esse processo contribui para estruturação de uma sociedade de homens efetivamente livres e plenamente cidadãos. Ou seja, é discutir e ajudar na busca de soluções para os problemas sociais, pois o verdadeiro cidadão está sempre na busca por uma sociedade mais justa.

De acordo com Marshall (1967), a cidadania requer "[...] um sentido direto de inclusão numa comunidade, baseado na lealdade a uma civilização que é propriedade comum". Cidadania é, portanto, a relação de direitos e deveres que os indivíduos têm perante a sociedade, não só os direitos sociais e políticos, mas o direito à informação e uma vida digna, pois só então se tem uma sociedade democrática, livre e mais justa.

Segundo a Constituição Federal de 1988, o termo democracia e cidadania tornaramse indissociáveis, mas para muitas pessoas pobres estes termos existem apenas no papel, pois o estado democrático de direito inexiste. Para muitos brasileiros, independentemente da situação em que cada um vive na sociedade, a cidadania, a democracia e a equidade não são dadas, mas conquistadas. Tal compreensão do ponto de vista sociológico, o termo cidadania vai muito além dos direitos básicos como o de votar, é uma construção social coletiva constante.

Nesse mesmo sentido, Pinzani e Rego (2015, p. 9) citam que:

Há diversa formas de as sociedades e de suas instituições entenderem a cidadania e, consequentemente, a própria democracia interferem, radicalmente, no estatuto da cidadania como princípio político 
indispensável à vida democrática. O conjunto dos direitos que compõem o complexo de prerrogativas de um(a) cidadão(ã) e, o que é fundamental, a efetivação concreta desses direitos na vida social são os verdadeiros indicadores do grau de profundidade de uma democracia.

Cidadania é também a preocupação constante com uma educação pública de qualidade para todas as pessoas que dela necessita. A escola como instituição social, juntamente com os educadores têm a missão de encontrarem alternativas para mediar junto aos menos favorecidos, na conquista de seus direitos e sonhos de uma vida melhor e mais justa, principalmente o direito a uma educação que inclua a todos. "A existência da cidadania como situação histórica supõe, necessariamente, um complexo de condições políticas, sociais, econômicas e culturais [...]" (PINZANI; REGO, 2015, p. 9).

\section{BREVE ANÁLISE DA POBREZA NO BRASIL E NO MARANHÃO}

Conforme o entendimento sobre os conceitos de pobreza, buscou-se conhecer as ideias de vários teóricos que abordam o assunto, cada um tem uma percepção diferente, mas existe um senso de pobreza de forma que ambos definem como sendo a privação ou ausência das necessidades básicas, e acesso mínimo as políticas de saúde, educação, saneamento básico, habitação, dentre outros direitos essenciais à vida das pessoas. "Em uma concepção mais imediata e generalizada, pobreza significa falta de renda ou pouca renda, um estado de carência, de privação, que pode colocar em risco a própria condição humana [...]". (LAVINAS, 2003, p. 29). Ou seja, são situações vivenciadas por milhares de famílias brasileiras.

Segundo o IBGE (2019), no período de 2012 a 2019 houve uma leve melhora nos níveis de carências de muitas famílias, mas ainda é grande o número de pessoas que vivem abaixo da linha de pobreza, "[...] o Maranhão foi a UF com maior percentual de pessoas com rendimento abaixo da linha, (53,0\%)". (IBGE, 2019, p. 59). Em contraponto com os outros Estados, que têm rendimentos mais elevados. O que evidência é que apesar de ter havido muitos avanços nas últimas décadas relacionado as políticas sociais, ainda é grande o número de brasileiros (as), que vivem em estado 
de plena carência. Porque para muitos faltam moradia digna, água tratada, comida, trabalho e outros direitos básicos.

Quanto a estrutura econômica 2017 a 2018, foi verificado pelo IBGE uma leve recuperação em alguns indicadores sociais analisado no país. Contudo, "[...] os menores índices desses indicadores concentraram nas regiões Norte e Nordeste, sendo o menor deles no Maranhão (R\$ 607)". (IBGE, 2019, p. 49). Isto é, o Maranhão é o Estado onde milhares de pessoas vivem em condições de pobreza extrema, com uma média de oito reais por dia. Isso acaba por impedir de certa maneira, que muitos adolescentes e jovens deixem de estudar para trabalhar e ajudar no sustento de suas famílias. De modo que os sonhos de uma vida melhor ficam cada vez mais distante, pois tendem a continuar em estado de plena carência.

Segundo Arroyo (2015, p. 10): "[...] a imagem dos(as) pobres como ausentes de valores também é reforçada pela mídia, ao mostrar a pobreza associada à violência e a crimes como o consumo e venda de drogas, furtos e roubos". De maneira que os governos têm inserido formas de organização que vem melhorando a vida de muitas crianças e jovens. Iniciativas como a modernização e combate à corrupção, tem ajudado a evitar desvios de recursos públicos voltados a melhoria da qualidade vida de milhares de famílias pobres. Contudo, muito ainda precisa ser feito para a melhoria da realidade social das pessoas que vivem em estado de plena carência no país, principalmente no Estado do Maranhão.

Arroyo (2015) menciona ainda, que a sociedade e o poder público, devem reconhecer que a pobreza e a desigualdade social existem e persistem, é um problema histórico e deve ser reconhecido e visto por todos como o limite da sobrevivência, pois são pessoas que não têm o suficiente para se alimentar três vezes ao dia. "O fato pobreza, qualquer que seja seu grau ou definição, é sempre assimilado ao problema da pobreza, seja no plano ideológico e moral, seja no plano político e econômico [...]" (LAVINAS apud DESTREMEAU; SALAMA, 2002, p. 108). De forma que as causas e consequências da pobreza são variadas e complexas, o que exigem estratégias de sobrevivências. 


\subsection{A POBREZA NAS ESCOLAS PÚBLICAS}

A pobreza vivenciada por muitas pessoas na sociedade é um desafio para as políticas públicas no sentido de minimizar as desigualdades sociais existentes no país, mas cada cidadão brasileiro pode dar a sua contribuição com incentivos e educação aos menos favorecidos, com o objetivo de amenizar as desigualdades sociais nas escolas públicas. Porque infelizmente, quanto mais pobre é a pessoa menos descrente ela se torna, pois a pobreza é uma questão social, econômica e política. De modo que Arroyo (2015, p. 10), "[...] considera-se que são carentes de valores, passa-se a entrever apenas uma solução educá-los (as) nos valores do trabalho, da dedicação e da perseverança, desde a infância".

De todo modo, a comunidade em geral pode exigir do poder público uma educação de qualidade que inclua todas as crianças e adolescentes em idade escolar, para educá-los não só no sentido de moralizá-los, mas de mostrar as condições e os meios necessários desses sujeitos saírem das condições de vitimados da ausência do poder público. Arroyo (2015) comenta ainda, que as escolas públicas estão cheias de crianças, adolescentes e jovens carentes e não se pode ignorar essa realidade. Pois milhares desses educandos, além de serem pobres quase sempre na sua maioria são negros, o que acarreta ainda mais os altos índices de discriminação. Alunos oriundos de famílias pobres das periferias, muitos ainda trabalham para ajudar no sustento de suas famílias, outros são influenciados pelos criminosos para praticarem pequenos furtos e outros crimes mais graves.

Todas as escolas de hoje, deveriam ser um espaço que possibilitassem a todos os alunos e alunas, a terem acesso a projetos culturais relevantes e significativos. Porque dar a oportunidades a esses educandos de aprenderem e criarem conhecimentos, é uma forma positiva de trabalhar os sonhos e sentimentos de cada um, e ampliar as perspectivas de sonharem com um futuro sem pobreza. Ou seja, é muito importante promover uma educação que resgate os interesse e necessidades dos educandos como um todo, redimensionando a importância do trabalho educativo, sua relação com o mundo do trabalho e com a vivência da cidadania. 
A permanência dos alunos e alunas na escola, é uma das condições para permanecerem no Programa Bolsa Família, mesmo que muitas famílias continuam em estado de carência. "A frequência escolar é uma condição necessária, mas não suficiente para garantir uma boa educação [...]" (PINZANI; LEÃO REGO, 2015, p. 25). Porque a escola precisa ser de qualidade, as crianças precisam de boas condições de estudo e principalmente ter o apoio e acompanhamento dos pais ou responsáveis. Sem essa ajuda fica praticamente impossível a criança obter bons resultados, conseguir avançar nos estudos e ter um nível de instrução suficiente para ter mais chances na vida profissional.

Arroyo (2010), enfatiza que os coletivos populares são mais uma vez o problema, ameaçando à ordem social. Porque o Estado e suas instituições políticas se oferecem como solução no sentido de manter as reações dos coletivos, feitos tão desiguais nos limites suportáveis para a segurança social, política e escolar. "No sentido de manter sob controle não tanto a produção do aumento das desigualdades, mas as reações dos coletivos feitos desiguais, inclusive crianças, adolescentes e jovens [...]". (ARROYO, 2010, p. 13).

\section{PERCURSO METODOLÓGICO}

A partir da revisão da literatura sobre a pobreza, desigualdade social, educação e cidadania, foi feita uma pesquisa de campo de natureza qualitativa com enfoque fenomenológico. "Na pesquisa qualitativa o pesquisador procura reduzir a distância entre a teoria e os dados, entre o contexto e a ação, usando a lógica da análise fenomenológica, pela sua compreensão dos fenômenos, descrição e interpretação [...]". (TEIXEIRA, 2009, p. 137). Ou seja, é nessa fase que devem ser tomadas decisões sobre áreas que necessitam de maior exploração e aspectos a serem enfatizados, a partir de um confronto entre os princípios teóricos do estudo e o que o pesquisador vai aprendendo durante a pesquisa.

Tendo em vista a natureza da pesquisa, foi feita opção pela coleta de dados por meio de observação direta, oficinas, conversas informais e entrevistas semiestruturadas com perguntas fechadas e abertas, pela flexibilidade de possuir apenas um roteiro 
básico, sem uma sequência rígida de perguntas. Propiciando assim, aos entrevistados discorrerem mais livremente sobre o tema proposto, na qual as perguntas foram mais significativas no decorrer de suas respostas. Nesse sentido, Triviños (1987, p. 146) comenta que:

A entrevista semiestruturada ao mesmo tempo em que valoriza a presença do investigador, favorece a descrição dos fenômenos sociais, além de oferecer todas as perspectivas possíveis para que o entrevistado alcance a liberdade e a espontaneidade necessária, enriquecendo a investigação.

Isto significa analisar de forma cuidadosa os registros da entrevista semiestruturada, realizada com os participantes da pesquisa. De tal maneira que a pesquisa compreendeu em atividades de investigação e compreensão das perspectivas de futuro, sonhos, educação e garantias da cidadania de crianças e adolescentes sob a condicionalidade da pobreza. A pesquisa foi realizada na Escola Municipal da Amizade situada na zona rural de Imperatriz - MA. Os participantes da pesquisa foram 40 alunos das turmas de $4^{\circ}$ e $5^{\circ}$ anos do ensino fundamental, a média de idade desses alunos foi de 9 a 11 anos de idade.

\subsection{ANÁLISE DOS DADOS COLETADOS}

Foram trabalhadas com os alunos na sala de aula, atividades práticas com oficinas, investigação com exposição oral e escrita com perguntas fechadas e abertas, a temática envolvendo sonhos, futuro pessoal e profissional, pobreza, educação e cidadania. A escolha desses alunos não foi aleatória, se deu pelo fato de eles já serem pessoas capazes de terem seus próprios pensamentos e desejos a cerca de um futuro melhor. Como cita um aluno do $4^{\circ}$ ano com 10 anos de idade: "o futuro para uma pessoa é como se todo mundo ruim tivesse acabado e tivesse chegado um mundo de alegria e não de tristeza". O aluno comentou ainda que vai ser um grande profissional, mas para isso precisaria estudar muito e terminar seus estudos.

Nesse sentido, Freire (1979) menciona que mudanças são necessárias para a adaptação do ser humano, não é um fim em si mesmo, mas apenas um dos momentos para a sua inserção no mundo e para a possibilidade dessa mudança se concretizar, 
pois o ser humano é um ser inacabado. De modo que é importante que crianças, adolescentes e jovens acreditem na mudança, no potencial que cada um tem, porque estudar faz toda a diferença na vida de uma pessoa. Afinal, a escola é um espaço social que tem como objetivo tornar o indivíduo participante ativo na sociedade.

No momento com os alunos foram expostos oralmente os conceitos de pobreza, educação, cidadania e sonhos de uma pessoa. Foi feito uma atividade escrita com as perguntas relacionadas a esses conceitos, de modo que eles puderam entender melhor o que estava sendo proposto, como mostra o gráfico 1 e 2 a seguir, com os resultados das atividades de investigação com os 40 alunos pesquisados.

GRÁFICO 1 - O Que é um sonho para você?

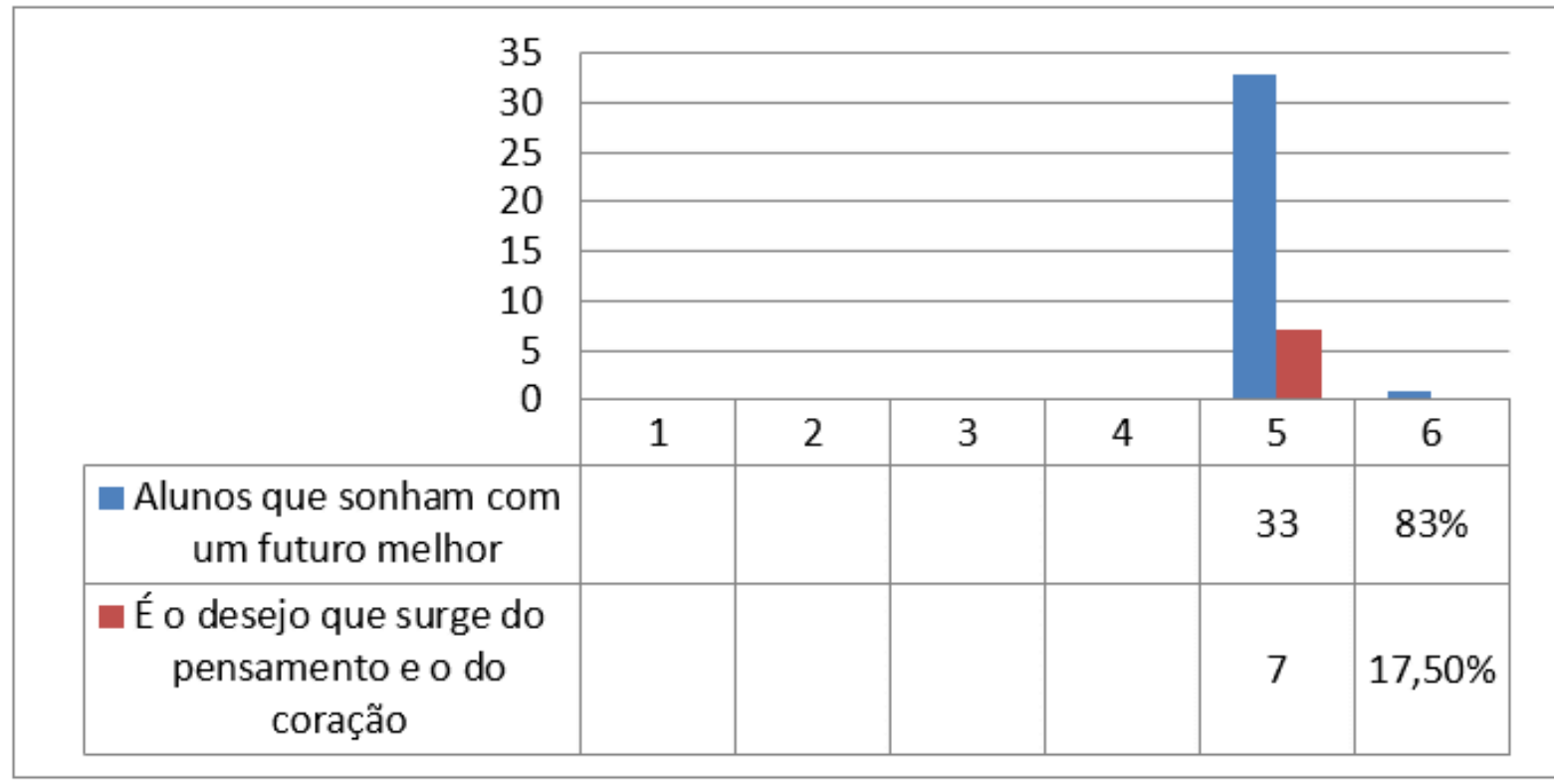

Fonte: Elaborado pela pesquisadora.

Nesse primeiro momento, os alunos têm a oportunidade de expressarem seus sonhos e desejos, o que evidenciam os desejos de mudanças na vida de cada um. Todos responderam que todas as pessoas têm direito de sonhar com um futuro melhor. Puderam expressar seus sonhos e desejos mais comuns sobre o que querem ser quando crescer, os sonhos apresentados foram: Advogado(a), Professor(a), Policial, Médico(a), Modelo, Engenheiro(a), Maquiadora, Veterinário(a), Jogador de Futebol, Enfermeira (o) e Delegado(a). Quanto ao futuro pessoal e profissional, 
quando tiverem com 25 ou 30 anos, puderam expressar também, que pretendem praticar boas ações com as pessoas na comunidade onde vivem e serem pessoas comprometidos(as) com a sociedade.

Dessa forma, a família independente da condição social que se encontre deverá ser a principal incentivadora dos sonhos dos filhos. Porque apesar de a escola pública ter suas precariedades, os educadores fazem o possível para desenvolverem um bom trabalho com os alunos. "A educação em si não se faz somente pela escola, mas com o poder de iniciativa e o espírito de cooperação social entre os pais, os professores, a imprensa e todas as demais instituições diretamente interessadas na obra da educação[...]." (AZEVEDO, 2006, p. 15). Logo, cabe cada um de nós educadoras e educadores, socializar com os nossos alunos e alunas na sala de aula, sobre a importância de os (as) mesmos (as) acreditarem e seguirem seus sonhos.

Em outro momento de diálogo com os alunos e alunas, perguntamos se eles se consideravam pessoas ricas com dinheiro ou pobres sem dinheiro, e se em algum momento foram discriminados na escola por seus colegas pela condição de serem ricos ou pobres. Um aluno comenta: "não sou rico com dinheiro e nem pobre sem dinheiro, não me sinto discriminado, porque meus colegas não são ricos também", ( $P$. L. 11 anos do $5^{\circ}$ ano).

Percebemos que grande parte desses alunos tinham a percepção de pobreza muito limitada sobre o verdadeiro significado da pobreza em suas vidas, pois muitos moram em casas doadas pelo Governo Federal, através do Programa Minha Casa, Minha Vida. Outros moram em invasões (terrenos invadidos), de modo que não se consideravam tão pobres. O que se pôde perceber também no diálogo com os educandos, foi o fato de eles considerarem as famílias que têm um carro, uma moto ou os dois por exemplo, serem pessoas ricas, de forma que em suas famílias nem todos tinham esses bens materiais.

No sentido de minimizar as desigualdades sociais entre os alunos, tendo a educação como garantias da cidadania de crianças e adolescentes sob a condicionalidade da pobreza, o Projeto Político Pedagógico da Escola (2017), abordava a educação no 
sentido amplo. Pois é a base primordial para mudanças de postura, atitude e hábitos de vida. É a transformação intelectual e social dos alunos através de uma educação de qualidade e desenvolvimento das mais diversas habilidades e competências de todas as crianças da escola.

Quanto aos casos de discriminação, sabemos que acontecem diariamente nas escolas entre alunos e alunas. Muitos desses alunos (as) não sabem, mas só o fato de apelidar um colega se referindo ao cabelo, a cor da pele, aparência física ou outra denominação, já é considerado como sendo uma atitude discriminatória e racista. Conforme Amaral (1998) comenta:

[...] a presença de preconceitos e a decorrente discriminação, vivida entre as pessoas são vistas com mais intensidade, pelos significativamente diferentes, impedindo-os, muitas vezes, de vivenciarem não só seus direitos de cidadãos, mas de vivenciar plenamente sua própria infância. (AMARAL, 1998).

Mas isso, não impede de promover a socialização entre os alunos no desenvolvimento de saberes importantes ao reconhecimento da cidadania, como mostra o segundo gráfico. Assim como, a possibilidade de sonharem com um futuro melhor.

GRÁFICO 2 - O que é ser um cidadão para você e como se pratica a cidadania?

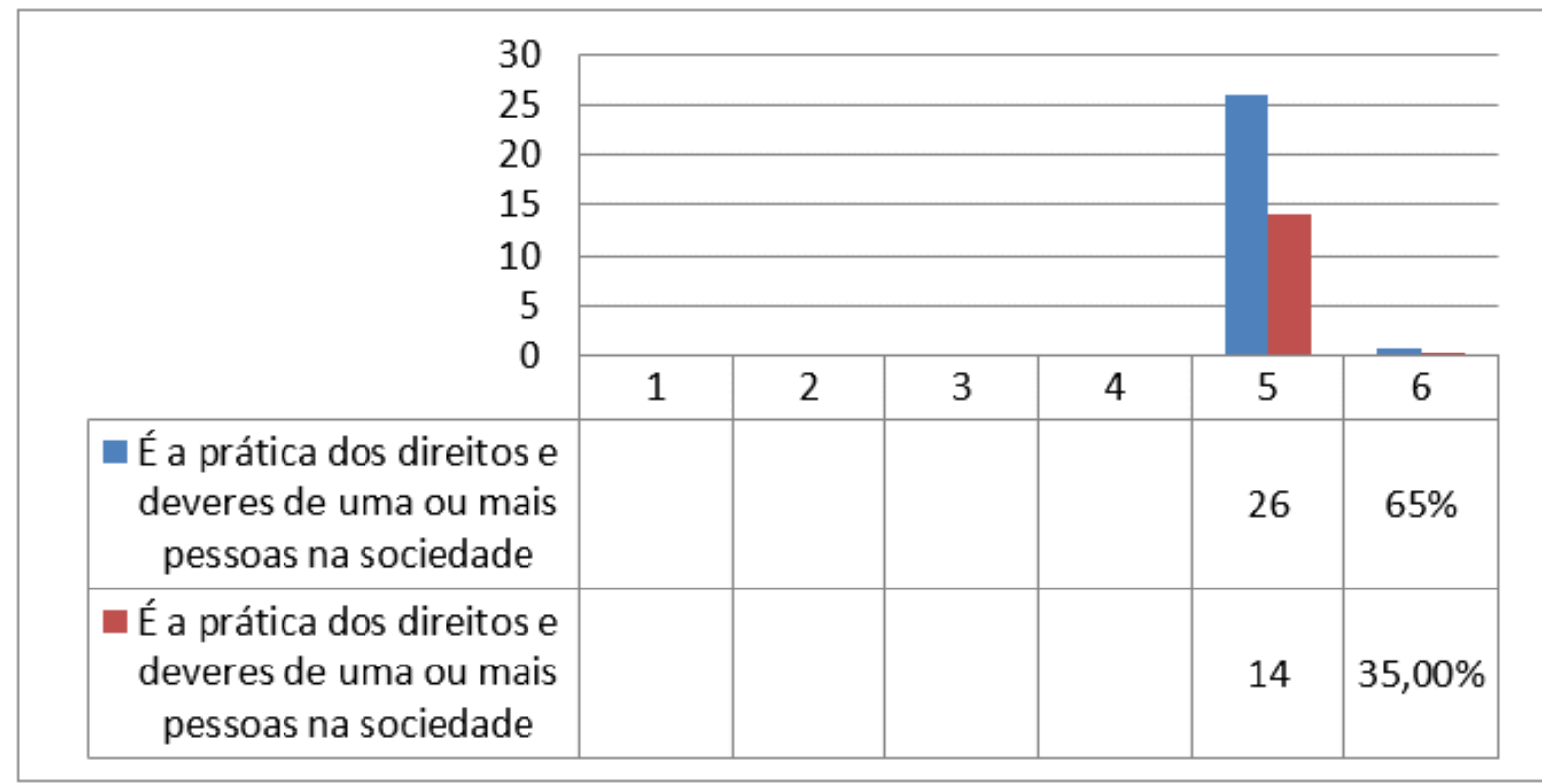

Fonte: Elaborado pela pesquisadora. 
De acordo o gráfico 2, com relação à concepção de cidadão e cidadania desses alunos, eles reconhecem como sendo direitos e deveres de uma pessoa e a verdadeira função do cidadão na sociedade. Entenderam também que é ter consciência de seus direitos e obrigações, garantindo que estes sejam colocados em prática, como por exemplo, uma educação que inclua a todas as crianças e demais pessoas. Conforme está explicitado nos Parâmetros Curriculares Nacionais da Educação Básica, Brasil (1997):

A escola, na perspectiva de construção de cidadania, precisa assumir a valorização da cultura de sua própria comunidade e, ao mesmo tempo, buscar ultrapassar seus limites, propiciando às crianças pertencentes aos diferentes grupos sociais o acesso ao saber, tanto no que diz respeito aos conhecimentos socialmente relevantes da cultura brasileira no âmbito nacional e regional como no que faz parte do patrimônio universal da humanidade. (BRASIL, 1997, p. 34).

Diante disso, entende-se que a escola pública tem a missão de melhorar as condições educacionais da sociedade, visando assegurar uma educação de qualidade aos educandos, em um ambiente de responsabilidade social e individual, como menciona o Projeto Político Pedagógico da Escola (2017). Tendo como objetivo, ser uma instituição reconhecida na sociedade pelas práticas educativas, pelo trabalho participativo, comprometido e inovador de uma equipe comprometida com a comunidade escolar, pautado nos valores como: respeito, inovação, participação e garantia de padrões de aprendizagens a todos os educandos, em conformidade com os Parâmetros Curriculares Nacionais da Educação Básica.

Foi perguntando também aos alunos se eles achavam a educação escolar importante, todos responderam que sim. Pois as pessoas que estudam têm mais facilidade de arrumar um emprego e ter uma profissão. De acordo com uma aluna: "a educação ensina muitas coisas, tira as pessoas das ruas, dos vícios, ensina a falar com as pessoas direito e pode sonhar com uma vida melhor para a família", (T. N. 11 anos, $5^{\circ}$ ano). O que se observou foi que essa aluna, já tinha uma opinião formada a respeito da importância de estudar, pois a escola, sendo uma instituição social é responsável por formar verdadeiros cidadãos e cidadãs, atuantes na sociedade e conscientes de seus direitos e deveres. 
Nesse sentido Leite (2015, p. 11) cita que em nossa sociedade, "[...] crianças e jovens assumem que tem características, valores, desejos, necessidades e condições de vida iguais, por isso torna-os homogêneo". Portanto, cheios de expectativas de uma vida melhor no futuro, e não é apenas sobre a possibilidade ou impossibilidade de viverem a infância ou a juventude, mas sobre os diferentes modos, como tais fases podem ser vividas. Uma vez que na sala de aula o professor e a professora como mediadores, podem apresentar várias situações e facilitar o contato dos alunos com elementos novos. A construção de um brinquedo, por exemplo, favorece o processo de integração das crianças na sala de aula, dessa forma elas passam a se conhecerem melhor e expressarem seus sonhos e desejos.

Os alunos foram unânimes em dizerem que sonhavam com coisas boas, eles enfatizaram que para realizarem esses sonhos precisavam estudar muito. Os seus pais e avós desejavam que eles pudessem estudar, crescer e terem a profissão que quisessem no futuro. Nenhum dos alunos e alunas manifestaram o desejo de seguir a profissão dos pais, pois muitos trabalham em hortas, outros de pedreiros, emprega doméstica, carroceiros ou outras profissões que não exigem muito estudo.

Um aluno citou: "se você não estudar e não ir para a escola, não vai ter uma profissão e você não será alguém na vida" (H. N. 11 anos, $5^{\circ}$ ano). De modo que conversamos com os educandos sobre a importância de eles acreditarem e seguirem os seus sonhos, sempre respeitando os colegas e familiares. Ou seja, a experiência vivenciada no ambiente escolar é fundamental para a construção de conhecimentos diversos e para a vida futura na sociedade.

Nessa perspectiva, a aprendizagem sistematizada é um caminho sobre o qual todo ser humano necessita passar, para sentir-se apto a desenvolver todo e qualquer papel perante a sociedade. "Hoje não se espera que o aluno desenvolva outras capacidades, o conteúdo passa a ser visto como meio para atingir algo maior, favorecer a formação do cidadão [...]" (REIS, 2011, p. 102). Logo, podemos dizer que crianças e jovens em situação de pobreza passam por momentos como infância e juventude e forma um grupo social diverso, vive e convive com diferentes grupos sociais com desejos e comportamentos diversificados. 
Segundo informações obtidas na secretaria da escola, havia em média 320 alunos matriculados, desses a maioria deles em torno de uns $70 \%$, recebiam o benefício do Programa Bolsa Família, pois eram crianças que dependiam desse pouco para garantia da sobrevivência. Nesse sentido, Brandão, Pereira e Dalt (2013) mencionam que em todas as regiões brasileiras, principalmente na região Nordeste, há avaliações negativas acerca do Programa Bolsa Família. Que caminha na direção de apontar que não há impacto no aproveitamento escolar, na ampliação do interesse em estudar por parte dos alunos e de suas famílias em acompanhar o desenvolvimento dos filhos na escola. À medida que muitos pais enviavam seus filhos para a escola era somente com a intenção de receber o benefício. Não estavam preocupados se os filhos estavam aprendendo alguma coisa ou com a frequência positiva deles, a preocupação maior era somente com o financeiro.

De acordo com informações obtidas através das educadoras das turmas pesquisadas, muitas crianças iam à escola por causa do lanche que era servido, pois não tinham em casa o suficiente para a primeira alimentação do dia. "O que temos em casa é para o almoço, não tem como comprar lanche", (Relata uma aluna do 4 ano, 9 anos). Nesse ponto, as crianças são muito sinceras, elas relatam o que realmente acontecem no seio familiar. Entende-se que os estudos em si, ou as atividades que esses alunos e alunas desenvolvem com os grupos não tem muita relevância para eles. Na realidade brasileira, muitos em estado de plena carência antes de concluir o ensino fundamental desistem de estudar e de sonharem com um futuro melhor.

Mesmo com tantos avanços o Brasil ainda precisa avançar quanto à redução da pobreza e do combate à fome. Pois em muitos estados brasileiros, assim como na região nordeste, o Maranhão é um dos estados que têm mais pessoas que vivem na extrema pobreza. Nesse cenário, as crianças, os adolescentes e jovens em idade escolar são os que mais sofrem, uma vez que a "[...] participação em relações sociais, políticas e culturais diversificadas e cada vez mais amplas, é fundamental para o exercício da cidadania na construção de uma sociedade democrática e não excludente". (BRASIL, 1997, p. 33). Logo, compreende-se como sendo a isenção 
social, respeito aos valores éticos, morais e de cidadania, necessária a vida dos diferentes grupos sociais.

\section{CONSIDERAÇÕES FINAIS}

Neste trabalho pudemos investigar as formas de pensar, sentir e agir de crianças sob condicionalidade de pobreza em uma escola pública. O que nos proporcionou um envolvimento com a realidade de crianças e adolescentes que viviam em condições precárias de subsistência. Tendo como principal referência à pobreza, a educação, cidadania e a realidade de muitas escolas públicas municipais brasileiras, os Gestores e Coordenadores têm um papel muito importante na transformação da realidade de milhares de crianças e jovens pobres.

Trabalho esse que envolve todo o corpo docente de uma escola principalmente os professores, que além de desenvolverem o papel de educadores têm a função de ensinar os valores de respeito e cidadania, valores estes que muitas crianças não aprendem com seus familiares, devido à falta de diálogo dever básico de convivência harmoniosa em qualquer família. Além disso, teve-se como objetivo compreender a realidade referente aos aspectos da pobreza e desigualdade social, em que vivenciam crianças e adolescentes de muitas escolas públicas municipais no Maranhão.

Foi dando ênfase a Escola Municipal da Amizade situada na zona rural de Imperatriz - MA, onde foi possível analisar e investigar as perspectivas de futuro pessoal e profissional, sonhos, pensamentos e sentimentos das crianças. Destacamos a realização das atividades de ação e reflexão e das oficinas, que foi muito importante para a compreensão da realidade dos educandos e suas famílias. O diálogo sobre educação escolar como garantia da cidadania, foi indispensável para a compreensão dos educandos sobre seus sonhos, desejos e visão de um futuro melhor para si e seus familiares.

O enfoque da pesquisa foi de natureza qualitativa com o caráter explicativo, e com a metodologia utilizada foi possível explorar além dos sonhos, pensamentos e sentimentos das crianças, mas o ponto de vista delas sobre educação e cidadania. A 
pesquisa com os alunos nos propiciou um conhecimento mais abrangente sobre as questões sociais dos educandos no ambiente escolar, suas opiniões e perspectivas de uma vida sem pobreza. Tendo a educação como principal aliada na compreensão de novos conhecimentos, para a vida futura.

Assim como, a igualdade de outros direitos necessários ao reconhecimento da cidadania, como sendo a base contínua para a transformação da realidade de milhares de crianças, adolescentes e jovens em condições de pobreza. Logo, percebemos que as normas da escola são pautadas na construção de uma educação que respeite o desenvolvimento integral dos educandos, seus direitos e deveres, pois essa escola como instituição social tem o compromisso de juntos com as famílias, sociedade e comunidade, de promoverem o desenvolvimento e socialização de alunos e alunas.

A apropriação de novos conhecimentos, nos possibilitou a realização de uma análise do espaço escolar onde esses sujeitos vivem diariamente, pois a escola é o melhor exemplo de onde tem pessoas comprometidas com a sociedade. De maneira que outros estudos e investigações poderão ser feitos a respeito deste assunto. Cita-se, Miguel G. Arroyo, Lúcia Helena A. Leite, Alessandro Pinzani e Valquíria Leão Rego e outros teóricos especialistas no assunto: pobreza, desigualdade social, educação e cidadania, como fonte pesquisa e de novos conhecimentos.

\section{REFERÊNCIAS}

AMARAL, Lígia Assumpção. Diferenças e Preconceitos na Escola: Alternativas teóricas e Práticas. Julio Groppa Aquino (org.) São Paulo Summus Editorial, 1998. Disponível em $<$ https://acessibilidade.ufg.br/up/211/o/Sobre_crocodilos_e_avestruzes_Ligia_Amar al_1_.pdf?1473202737>. Acesso em: 10 jan. 2017.

ARROYO, Miguel Gonzalez. Pobreza, Desigualdades e Educação. [2015]. Disponível em:<http://catalogo.egpbf.mec.gov.br/modulos/intro/elemento.html/2015. Acesso diário em 2015/2016>. Acesso em: 21 jan. 2017. 
AZEVEDO, Fernando de et al. 0 manifesto dos pioneiros da Educação Nova. HISTEDBR, Campinas, ago. 2006, p. 188-204. Disponível em: $<$ http://www.histedbr.fe.unicamp.br/revista/edicoes/22e/doc1_22e.pdf/catalogo.egpbf. mec.gov.br/modulos/mod-3/referencias.html>. Acesso em: 26 de jul. 2016.

BRANDÃO, André; PEREIRA, Rita de Cássia; DALT, Salete. Programa Bolsa Família: percepções no cotidiano da escola. Política e Trabalho. Revista de Ciências Sociais, Fortaleza, n. 38, p. 215-232, abr. 2013. Disponível em: <http://periodicos.ufpb.br/ojs/index.php/politicaetrabalho/article/viewFile/14312/9388> . Módulo I. Pobreza e Cidadania: http://catalogo.egpbf.mec.gov.br/modulos/mod1/abertura.html/2014. Acesso em: 25 nov. 2015.

BRASIL, Lei de Diretrizes e Bases. Lei oํ 9.394/96, de 20 de dezembro de 1996.

BRASIL. Constituição (1988). Constituição da República Federativa do Brasil. Brasília, DF: Senado Federal: Centro Gráfico, 1988. 292 p.

BRASIL. Secretaria de Educação Fundamental. Parâmetros Curriculares Nacionais: introdução aos parâmetros curriculares nacionais / Secretaria de Educação Fundamental. Brasília: MEC/SEF, 1997. 126 p. Disponível em:< http://portal.mec.gov.br/seb/arquivos/pdf/ivro01.pdf>. Acesso em: 03 jan. 2017.

DESTREMEAU, B.; SALAMA, P. Medição e excessos de pobreza. Paris: PUF, p. 18, 2002.

FREIRE, Paulo. Pedagogia do Oprimido. Rio de Janeiro: Paz e Terra, 17 ed., 2005.

GHIRALDELLI JR., P. Introdução à Educação Escolar Brasileira: História, Política e Filosofia da Educação [versão prévia] - 2001. Disponível em:< https://pedagogiaaopedaletra.s3.amazonaws.com/wpcontent/uploads/2013/04/EDUCA\%C3\%87\%C3\%83O-BRASILEIRA.pdf>. Acesso em 30 de nov. 2016. 
INSTITUTO BRASILEIRO DE GEOGRAFIA E ESTATÍSTICA - IBGE. Síntese de indicadores sociais: uma análise das condições de vida da população brasileira: Coordenação de População e Indicadores Sociais. - Rio de Janeiro: IBGE, 2019. Disponível em: <https://biblioteca.ibge.gov.br/visualizacao/livros/liv101678.pdf>. Acesso em: 28 de ago. 2020.

LEITE, Lúcia Helena Alvarez. Escola: Espaços e Tempos de Reprodução e Resistências da $\quad$ Pobreza. Disponível em:<http://catalogo.egpbf.mec.gov.br/modulos/mod-3/>. Acesso em: 21 jan. 2017.

MARSHALL, T. H. Cidadania e classe social. In:_. Cidadania, classe social e status. Rio de Janeiro: Zahar Editores, 1967. p. 57-114.

PINZANI, Alessandro; LEÃO REGO Valquíria. Pobreza e cidadania: Módulo I, 2015. Disponível em: <http://catalogo.egpbf.mec.gov.br/modulos/mod1/abertura.html/2015>. Acesso em: 2015/2016.

PREFEITURA MUNICIPAL DE IMPERATRIZ. Projeto Político Pedagógico. Secretaria de Educação, Esporte e Lazer- SEMED. Imperatriz - MA, 2017.

REIS, Teuler. Educação e Cidadania: a batalha de uma Educação comprometida. Rio de Janeiro: Wak Editora, 2011. 136p.

TEIXEIRA, Elizabeth. As três metodologias: acadêmica, da ciência e da pesquisa. 6. ed. , Petrópolis, RJ: Vozes, 2009.

TONET, Ivo. Educação, Cidadania e Emancipação Humana. ljuí: Ed. Unijuí, 2005, 256

Disponível

em:

$<$ http://ivotonet.xpg.uol.com.br/arquivos/EDUCACAO_CIDADANIA_E_EMANCIPAC AO_HUMANA.pdf>. Acesso em 28 nov. 2016.

TRIVIÑOS, A. N. S. Introdução à Pesquisa em Ciências Sociais: a pesquisa qualitativa em educação. São Paulo: Atlas, 1987.

Enviado: Outubro, 2020. 
Aprovado: Outubro, 2020. 